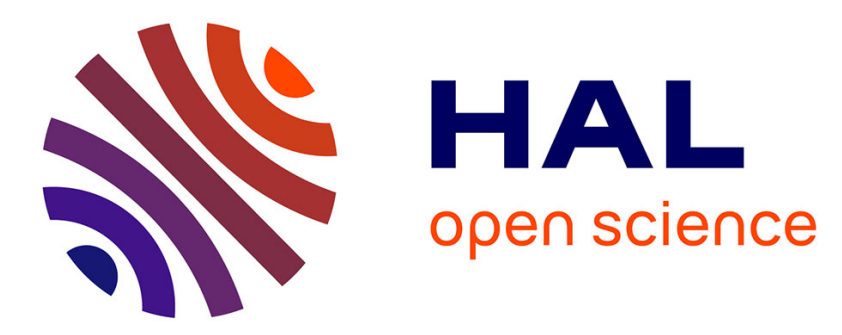

\title{
Percutaneous vertebroplasty to treat painful myelomatous vertebral deposits-long-term efficacy outcomes
}

Paula Garland, Philip Gishen, Amin Rahemtulla

\section{To cite this version:}

Paula Garland, Philip Gishen, Amin Rahemtulla. Percutaneous vertebroplasty to treat painful myelomatous vertebral deposits-long-term efficacy outcomes. Annals of Hematology, 2010, 90 (1), pp.95-100. 10.1007/s00277-010-1021-2 . hal-00554993

\section{HAL Id: hal-00554993 \\ https://hal.science/hal-00554993}

Submitted on 12 Jan 2011

HAL is a multi-disciplinary open access archive for the deposit and dissemination of scientific research documents, whether they are published or not. The documents may come from teaching and research institutions in France or abroad, or from public or private research centers.
L'archive ouverte pluridisciplinaire HAL, est destinée au dépôt et à la diffusion de documents scientifiques de niveau recherche, publiés ou non, émanant des établissements d'enseignement et de recherche français ou étrangers, des laboratoires publics ou privés. 


\section{Editorial Manager(tm) for Annals of Hematology}

Manuscript Draft

Manuscript Number: AOHE-D-10-00158R1

Title: Percutaneous Vertebroplasty to Treat Painful Myelomatous Vertebral Deposits - Long Term Efficacy Outcomes

Article Type: Original Article

Keywords: percutaneous vertebroplasty; myeloma; pain

Corresponding Author: Dr Paula Garland,

Corresponding Author's Institution:

First Author: Paula Garland

Order of Authors: Paula Garland; Philip Gishen; Amin Rahemtulla

\section{Abstract: Abstract}

Objectives. Developed for benign conditions including osteoporotic fractures and haemangiomas, vertebroplasty has since been employed in neoplastic lesions, including myeloma. Advances in myeloma treatments, yielding improved survival times, have led to an increasing need for effective therapies that improve quality of life. The first randomised trials of vertebroplasty to treat painful osteoporotic crush fractures, have cast doubt of its benefit over a placebo procedure, with a proposed rationale that fracture healing over time may account for the non-superiority results. However these findings cannot be extrapolated to myeloma, where the pathology is one of progressive bony destruction, coupled with a failure of new bone formation. Here, we present the outcome data for myeloma patients treated at our tertiary-referral centre over a $5 y$ r period, focusing on both subjective and objective measures of efficacy and safety.

Patients/Methods. Records were reviewed to extract pain-score, function and analgesia pre/post procedure. Where possible, patients were then contacted directly and asked to assess their benefit by grading change in pain-score, analgesia use and mobility. Performance status was assessed using the Eastern Cooperative Oncology Group (ECOG) scale.

Results. Of 26 patients treated for painful, thoraco-lumbar lesions, 77\% reported improved pain-score $(\mathrm{P}<0.003)$. Analgesia reduction, better mobility and improved performance-status were also seen. Conclusion. Our data support the consideration of vertebroplasty as a first-line treatment for painful, myelomatous vertebral disease. Prospective, randomised studies are now required to further define its role.

Response to Reviewers: Please see the attached file for our response to the reviewers comments. 
Conflict of interest

Click here to download Conflict of interest: ann hem.pdf 
Ref.: Ms. No. AOHE-D-10-00158

Percutaneous Vertebroplasty to Treat Painful Myelomatous Vertebral Deposits - Long Term Efficacy Outcomes

Annals of Hematology

Dear Dr Garland,

Reviewers have now commented on your paper. You will see that they are advising that you revise your manuscript. If you are prepared to undertake the work required, I would be pleased to reconsider my decision.

The reviewers' comments can be found at the end of this email or can be accessed by following the provided link.

If you decide to revise the work, please submit a list of changes or a rebuttal against each point which is being raised when you submit the revised manuscript.

Your revision is due by $10-07-2010$.

To submit a revision, go to http://aohe.edmgr.com/ and log in as an Author. You will see a menu item call Submission Needing Revision. You will find your submission record there.

Yours sincerely

Arnold Ganser, M.D.

Editor-in-Chief

Annals of Hematology

Reviewers' comments:

Reviewer \#1: The submitted work by Garland et al. is a single-institution retrospective analysis of all myeloma patients treated between 2004 and 2009 with vertebroplasty for painful thoraco-lumbar bone lesions. 26 patients were identified, and they were treated at one (8 patients), two (5 patients) or three (13 patients) vertebral levels. After a mean follow-up of 19 months, 20 patients reported an improvement in pain, 16 patients were able to reduce analgesic medications, and 16 patients reported a significant improvement in mobility. Ten patients had died at the time of the study.

Painful vertebral fractures are a common complication of multiple myeloma, and standard treatment consists of analgesics, bisphosphonates, radiotherapy, and systemic antimyeloma 
treatment. Surgery is usually reserved for patients with unstable fractures or neurologic complications. Vertebroplasty and balloon kyphoplasty are minimally invasive surgical techniques where bone cement is injected into affected vertebrae. Several small phase II studies (references 5, 7-9 and review by Bouza et al. 2009) have shown that these procedures are safe, provide early and sustained pain relief and improve functional outcomes in myeloma patients. Two randomized studies of vertebroplasty published in 2009 failed to show a clear benefit for patients with painful osteoporotic fractures, but no randomized trials have yet been reported for myeloma patients.

The present study addresses an important question in the management of myeloma patients with painful thoraco-lumbar bone lesions. With 26 patients it is one of the larger reports in this indication. The findings are consistent with earlier published reports and support the notion that the results from the randomized trials in osteoporosis aren't necessarily applicable to myeloma patients.

Unfortunately the study does not provide significant new information in the present form, as the questions addressed do not differ from several previously published studies. The authors provide little guidance on how myeloma patients were selected for vertebroplasty. This is obviously more difficult to do in a retrospective analysis, but some data can probably be collected. Were patients with unstable fractures, spinal cord compression or without symptoms correlating with bone lesions excluded? And how many patients were offered vertebroplasty, but declined the procedure?

>The myeloma patients were selected for consideration of vertebroplasty on a case by case basis, initiated by their treating haematologist who organised imaging consisting of plain Xrays, MRI scan and in some cases bone scan. Referral with the results of these investigations were made to the interventional radiologist who assessed for lesions that may be causing the symptoms that were amenable to treatment. Referral was based on pain refractory to systemic analgesia or requiring unacceptably high / problematic doses of opiates as judged by the patient and haematologist by their symptoms of pain and medication related side effects. This information has now been included in the discussion as paragraph 4 .

>Patients with acute spinal cord compression were not excluded empirically. Multidisciplinary team evaluation of patients with neurological deficit was carried out involving neurosurgical and interventional radiology specialists and percutaneous vertebroplasty was considered in patients not requiring immediate surgery or with lesions not amenable to surgical fixation. Percutaneous vertebroplasty would also be considered for patients not appropriate for surgery based on their performance status. This information has now beein included in the discussion as paragraph 5 . 
>Because of the retrospective nature of this study, we are unable to provide accurate information on the number of patients who were offered vertebroplasty but declined the procedure. In answer to the reviewers enquiry, our lead myeloma haematology Consultant is able to provide an approximate estimate that $5 \%$ of patients offered vertebroplasty do accept and proceed to have the procedure performed. However we are unable to base this estimate on hard data so have elected not to quote it in the manuscript. It is certainly important information as the reviewer has highlighted and we should aim to collect this data in a prospective fashion in future.

The authors do not report systemic antimyeloma treatment, radiotherapy to the spine, bisphosphonate treatment or surgery before or after vertebroplasty. This information would put the efficacy data into a larger context, e.g. by showing that most patients had severe pain despite these interventions prior to vertebroplasty. The authors report on page 11, 2nd paragraph, that the majority of patients whose pain returned had progression of myeloma. It would be helpful to have more information about the disease status at the time of vertebroplasty and at the time of the study to better understand if patients with progressive disease benefit from vertebroplasty (or whether they should first receive antimyeloma treatment), and how loss of benefit from vertebroplasty relates to disease progression.

$>23$ of the 26 patients received systemic antimyeloma chemotherapy prior to the vertebroplasty procedure. In three patients, the diagnostic bone biopsy was taken at the same time as the symptomatic vertebral lesion being treated. Two went on to receive systemic antimyeloma treatment after the procedure, one patient died before chemotherapy was initiated.

Information on date of myeloma diagnosis, vertebroplasty date, systemic antimyeloma treatment, bisphosponate treatment, radiotherapy and surgery has been added to Table of individual patients (now Table 1 in the revised manuscript in response to comments from Reviewer 2) and details of the data have been added to results and discussion section to provide a greater degree of context for the vertebroplaty procedure for each patient, as suggested - Results paragraph 2, discussion paragraph 6

The discussion does not address the differences between vertebroplasty and balloon kyphoplasty, whether balloon kyphoplasty was performed in myeloma patients, and why vertebroplasty was chosen as the procedure of choice.

>Percutaneous vertebroplasty involves the injection of cement into the vertebra directly through the needle accessing the lesion. Balloon kypohplasty involves the insertion of a balloon into the vertebra aiming to expand the vertebral height on inflation. Cement is then injected into the cavity. The benefits of one procedure over the other is a topic of debate in the interventional radiology community (Ref 14-16 added) Balloon kyphoplasty theoretically 
allows the cement to be injected under less pressure, theoretically reducing the risk of cement / fat embolism. However data to support this is sparse. The balloon inflation also provides some degree of restoration of vertebral height, however this is usually in the order of a few milimetres. The opinion within our interventional radiology department is that percutaneous vertebroplasty is simpler, quicker - allowing for shorter anaesthetic or in select cases even local anaesthesia, cheaper and provides the same degree of post procedure strength to the vertebral body. All of our patients were treated with percutaneous vertebroplasty as opposed to balloon kyphoplasty as is our local departmental policy agreed by our haematology and interventional radiology department. A brief explanation of these differences and our departmental policy has been included in the discussion section - paragraph 4 .

The authors do not state that the study has been performed in accordance with the ethical standards laid down in the Declaration of Helsinki, and whether patients that were interviewed had given their informed consent.

>This statement has been added in the first paragraph of the materials and methods section.

Bouza et al. Balloon kyphoplasty in malignant spinal fractures: a systematic review and metaanalysis. BMC Palliat Care 2009 doi:10.1186/1472-684X-8-12

Minor comments:

Page 19: Fig. 1 does not add any new information.

$>$ We have altered the legend to make the figure more informative

Reviewer \#2: This is a retrospective analysis on the effect of vertebroplasty in patients with multiple myeloma. Pain reduction was seen in the majority of patients but only a rather crude pain scale was used. These data can serve as basis for a prospective randomized trial as suggested by the authors.

Minor Point:

ECOG scale should be familiar to every oncologist. Therefore Table I should be omitted. 



\title{
Percutaneous Vertebroplasty to Treat Painful Myelomatous
}

\section{Vertebral Deposits - Long Term Efficacy Outcomes}

\author{
Dr. Paula Garland ${ }^{l}$, Prof. Phillip Gishen ${ }^{2}$, Dr. Amin Rahemtulla ${ }^{l}$
}

1. Department of Haematology, Imperial College Healthcare NHS Trust, Hammersmith Hospital, Du Cane Road, London, London W12 0NN, UK

2. Department of Radiology, Imperial College Healthcare NHS Trust, Charing Cross Hospital, Fulham Palace Road, London, W6 8RF, UK

\section{Corresponding Author:}

\section{Dr. Paula Garland p.garland@imperial.ac.uk}

\begin{abstract}
Objectives. Developed for benign conditions including osteoporotic fractures and haemangiomas, vertebroplasty has since been employed in neoplastic lesions, including myeloma. Advances in myeloma treatments, yielding improved survival times, have led to an increasing need for effective therapies that improve quality of life. The first randomised trials of vertebroplasty to treat painful osteoporotic crush fractures, have cast doubt of its benefit over a placebo procedure, with a proposed rationale that fracture healing over time may account for the non-superiority results. However these findings cannot be extrapolated to myeloma, where the pathology is one of progressive bony destruction, coupled with a failure of new bone formation. Here, we present the outcome data for myeloma patients treated at our tertiary-referral centre over a 5yr period, focusing on both subjective and objective measures of efficacy and safety.
\end{abstract}


Patients/Methods. Records were reviewed to extract pain-score, function and analgesia pre/post procedure. Where possible, patients were then contacted directly and asked to assess their benefit by grading change in pain-score, analgesia use and mobility. Performance status was assessed using the Eastern Cooperative Oncology Group (ECOG) scale.

Results. Of 26 patients treated for painful, thoraco-lumbar lesions, $77 \%$ reported improved pain-score $(\mathrm{P}<0.003)$. Analgesia reduction, better mobility and improved performance-status were also seen.

Conclusion. Our data support the consideration of vertebroplasty as a first-line treatment for painful, myelomatous vertebral disease. Prospective, randomised studies are now required to further define its role.

Keywords: percutaneous vertebroplasty; myeloma; pain 


\section{Introduction}

Back pain is one of the most common presenting symptoms of multiple myeloma and approximately $60 \%$ of patients have vertebral involvement at diagnosis, primarily between T6 and L4. ${ }^{1}$ Along with control of tumour burden, the reduction of disease related symptoms is of utmost importance, yet with the advancement of novel antitumoral agents, skeletal morbidity may persist, decreasing the quality of life of patients who otherwise benefit from improved survival times and longer time to disease progression.

The management of painful, myeloma bone disease traditionally combines medical therapies, including analgesics, bisphosphonates, steroids and chemotherapy with radiotherapy and surgical intervention. Surgery is usually employed for lesions that threaten neurological function and whilst radiotherapy is often efficacious, effect onset may be delayed and the dose of radiation limited by proximity to the spinal cord. Side effects from opiate analgesia can be problematic, particularly since myeloma patients are often older. The use of non-steroidal anti-inflammatory drugs (NSAIDs) js limited by their nephrotoxicity.

\footnotetext{
Since its initial use to treat benign, vertebral haemangiomas ${ }^{2}$ percutaneous vertebroplasty has been applied in the treatment of a range of conditions including osteoporotic crush fractures ${ }^{3}$, bone metastases ${ }^{4}$ and increasingly for back pain control in myeloma. ${ }^{5}$
} 
We have performed a comprehensive review of vertebroplasty for patients with multiple myeloma treated at our tertiary-referral centre over a 5yr period between 2004-2009. 


\section{Materials and Methods}

\section{Patients}

All vertebroplasties performed at Imperial College Healthcare NHS Trust between 2004 and 2009 were retrospectively reviewed. Patients treated for myeloma were identified and their records reviewed extracting baseline characteristics, pain score, analgesic regimens pre/post procedure and complication rates. Where possible, patients were then contacted directly and graded pain score, analgesia use, mobility post-procedure, duration of benefit and performance status assessed using the Eastern Cooperative Oncology Group (ECOG) scale. ${ }^{6}$ No patient was excluded from the analysis. The study was performed in accordance with the ethical standards laid down in the Declaration of Helsinki, and patients that were interviewed gave their informed consent.

\section{Vertebroplasty Procedure}

Imaging including plain radiographs, MRI and isotope bone scan, were reviewed and vertebra(e) for intervention identified. Vertebroplasty was performed under a short general anaesthetic with the patient in a lateral position, under fluoroscopic X-ray guidance. Vertebral access was via a transpeduncular approach (Figure 1) employing a 7-gauge, 160mm Gishen bone-biopsy needle to inject 1-4ml of PMMA cement. The PMMA cement was made from $9.0 \mathrm{~g}$ of Kyphx high viscosity, radio-opaque fluid mixed with $20.0 \mathrm{~g}$ of Kyphx cement powder (68\% methyl-methacrylate-styrene copolymer, $30 \%$ barium sulphate, $2 \%$ benzoyl-peroxide). Post-anaesthetic all patients were questioned for neurological function and pain level. 


\section{Analysis}

Due to the retrospective nature of the study, pre/post procedure pain scores were on a three point, mild/moderate/severe scale. Patients we contacted were also assessed using a 10 point score. The whole cohort was analysed for reduction in pain score yes/no; and for the fifteen patients interviewed, mean pain score reduction calculated with P value derivation (Wilcoxon Signed-Rank Test). 


\section{Results}

\section{Demographics/Follow-Up}

132 vertebroplasty procedures were performed at Imperial College Healthcare NHS Trust over the study period. Of these, 26pts were treated for painful lesions secondary to myeloma. Baseline characteristics are detailed in Table I. Mean age was 59.3yrs, range 42-76yrs. Fifty-seven vertebrae were treated between T6-L5 levels. Eight patients had a single vertebra treated, five had two and thirteen three levels simultaneously.

Follow-up ranged 20 days to 42 months, mean 19 months. At the time of the study, ten patients had died. As shown in Table I, 23/26 patients received systemic antimyeloma chemotherapy prior to the vertebroplasty procedure and 20/26 patients were treated with bisphosphonate therapy. Eleven patients received radiotherapy prior to the vertebroplasty and 4 afterwards. One patient was treated with radiotherapy both prior to and after the vertebroplasty. Two patients had had surgical intervention prior to receiving the vertebroplasty and 1 after.

\section{Efficacy}

$65 \%$ of patients rated their pain as severe and $35 \%$ as moderate prior to the procedure. Seventy-seven percent reported a reduction in their pain score after the procedure (Table I). Seven patients (26\%) reported some benefit on waking from the anaesthetic, which then improved further over the following days/weeks. Median time to improvement was 3 days. $87.5 \%$ reported a reduction in their pain score if they had one vertebral level treated, $40 \%$ if they had two and $77 \%$ if three levels were 
treated. Twelve patients were available for interview. Ten patients had died, one had moved abroad and three could not be contacted. Of those twelve, eleven reported a benefit, with mean reduction in pain score of $4.7 / 10(\mathrm{P}<0.003)$. Where patients reported benefit, it was sustained for a mean of 13.5 months (range 1.5-35 months). The majority whose pain returned had concurrent progression of myeloma. $58 \%$ of patients were able to reduce their systemic analgesia: 9 stopped all forms of opiate analgesia and the others reduced their dose by 30-75\%. Mean opiate dose reduction was $45.6 \%$. $58 \%$ reported a significant improvement in mobility and 5 had an improvement in ECOG score - primarily due to being able to recommence work.

\section{Safety/Complications}

The procedure was generally very well tolerated. Three patients had a small $(<1 \mathrm{ml})$ cement leak, noted at the time of the procedure. Two leaks were associated with increased pain on waking from anaesthetic, which was uncomplicated and resolved within 24hrs. Six others, without cement leak, experienced peri-procedure pain which again resolved within 24hrs. There were no cement or fat emboli, bleeding or infections. The only clinically significant complication was anaesthetic related respiratory compromise in a patient with pre-existing lung problems which resolved within $72 \mathrm{hrs}$. 


\section{Discussion}

The results of this study serve to confirm and extend those reported in recent literature. We have shown that percutaneous vertebroplasty is a safe and effective modality of treatment with $77 \%$ of recipients reporting a reduction in their pain score that began, in a quarter of patients, as early as waking from the anaesthetic. Our results also show that significant reduction in systemic analgesia is possible with over $1 / 3$ of patients able to stop all opiate analgesia. The withdrawal of these medications has a positive impact on patients' wellbeing, eliminating troublesome and frequent side effects such as sedation and constipation.

Most studies examining percutaneous vertebroplasty in multiple myeloma have involved limited patient numbers $(<15)$ with the majority of patients being treated at a single vertebral level..$^{7-9} 50 \%$ of the patients in our study were treated at three vertebral levels simultaneously. It has been postulated that the treatment of multiple levels may improve outcomes due to a lessening of the risk of fracture involving vertebrae neighbouring a cemented level and uncovering pain in adjacent vertebrae. ${ }^{5}$ We did not however reproduce this finding in our data, perhaps because a larger cohort is required to reveal more subtle differences in treatment effect.

The first, recently reported, randomised controlled studies in osteoporosis were unable to demonstrate superiority of cementoplasty over a sham procedure. ${ }^{10,11}$ One possible explanation is that natural healing over time accounts for a large proportion of the improvement seen. However, in contrast to osteoporosis, the pathology of myeloma; via the up-regulation of RANK (receptor activator of nuclear factor kappa B)-RANK 
ligand interaction, down-regulation of osteoprotegerin and up regulation of dickkopf$1 ;^{12,13}$ is one of progressive bony destruction and failure of healing mechanisms. It is therefore not possible to extrapolate the results of these trials to the malignant setting.

The myeloma patients treated at our institution were selected for consideration of vertebroplasty on a case by case basis, initiated by their treating haematologist who organised imaging consisting of plain Xrays, MRI scan and in some cases an isotope bone scan. Referral with the results of these investigations were made to the interventional radiologist who assessed for lesions that may be causing the symptoms that were amenable to treatment. Referral was based on pain refractory to systemic analgesia or requiring unacceptably high / problematic doses of opiates as judged by the patient and haematologist according to symptoms of pain and medication related side effects. In accordance with out local policy agreed by our haematology and interventional radiology departments, all of our patients were treated with percutaneous vertebroplasty as opposed to balloon kyphoplasty, which involves the injection of cement under lower pressure into a cavity created by balloon inflation within the vertebra being treated,. The advantages of each type of procedure is a topic of much debate ${ }^{14-16}$, a full review of which is outside the scope of this article, However minimal vertebral height gain is the main differences achievable with kyphoplasty. This is however usually only a few millimetres and is balanced against longer procedure and hence anaesthetic time and higher procedure related costs.

Patients with acute neurological presentation are not empirically excluded from undergoing therapeutic vertebroplasty at our centre and three patients in our cohort with acute neurological symptoms, two with cord compression (patients 5 and 10) and 
one with L3 root compression (patient 11) were treated with vertebroplasty as first line therapy. All received subsequent radiotherapy and one (patient 10) had surgical fixation 4 months later. Our standard practice includes, multidisciplinary team evaluation of patients with neurological deficit involving haematological, neurosurgical and interventional radiology specialists. Percutaneous vertebroplasty may be considered in patients not requiring immediate surgery or with lesions not amenable to surgical fixation as well as for patients not appropriate for surgery based on their performance status. As the experience in our cohort suggests, vertebroplasty can be successfully combined with radiotherapy both prior and afterwards. There is however some evidence suggesting that optimal results are achieved by performing vertebroplasty first. ${ }^{17}$ As we saw, it has also been successfully employed with surgical instrumentation. $^{18}$

As well as a favourable biomechanical profile with increase in vertebral body strength, ${ }^{19}$ the possibility of a local anti-tumoral component to PMMA cement treatment, ${ }^{20}$ has also been reported with cementoplasty, although clearly any local tumoricidal effects are likely to be insignificant in the anti-myeloma treatment of myeloma which requires a systemic approach. 23/26 of our cohort had received systemic chemotherapy prior to their vertebroplasty. In three remaining patients, the diagnostic bone biopsy was taken at the same time as the symptomatic vertebral lesion being treated. Two went on to receive systemic antimyeloma treatment after the procedure, one patient died before chemotherapy was initiated. Clearly systemic therapy is key in the control of myelomatous disease, although from a point of view of bony lesions may be inadequate, even in combination with bisphosphonate therapy, in the control of pain from already damaged vertebrae - as was seen in our cohort. 
Of particular relevance when treating myeloma patients, care must be taken to correct for post-vertebroplasty artefact when using imaging, particularly PET/CT to monitor disease progression. $^{21,22}$

The most serious potential complications of vertebroplasty are cement leakage posteriorly into the spinal canal which may cause nerve root irritation or cord compression and embolisation of either the cement or extravasated fat. Minimising the risk of the latter is why our institution treats a maximum of three levels at one sitting. Small leaks of cement in other directions i.e. superiorly/inferiorly/laterally are usually irrelevant. Bleeding and infective complications have been consistently low among other studies ${ }^{8,19}$ and we experienced neither in our cohort.

Our study involved treatment of the thoraco-lumbar spine, although reports of cervical spine treatment, pelvic bones and non weight bearing regions such as the sternum are emerging. ${ }^{23-25}$ We employed a postero-lateral approach, although novel approaches including anterior and even trans-oral access of the cervical spine have been reported.

This study was limited by the relatively small number of patients and its retrospective nature. The lack of a prospectively completed questionnaire meant that we relied on a three point pain score as recorded by the treating physicians in the medical notes at the time. For those patients interviewed, reports of function and pain score could have been affected by recall bias. These limitations could be overcome by future randomised, multicentre, prospectively designed trials. 


\section{Conclusion}

Despite the results of the first randomised controlled vertebroplasty trials in osteoporosis, we believe this procedure is a safe and effective treatment option for painful myelomatous bone disease that is still underutilised within the United Kingdom. It can frequently allow for withdrawal of opiate-based regimens and thus averting their side effects and, if used as an upfront therapy, may avert prolonged periods of sub-optimally controlled pain. Larger scale, prospective, randomised studies are now required to further define the role of this treatment for a patient population that is potentially expanding in line with advances in existing treatment strategies and emerging innovative therapies.

\section{Acknowledgements}

We would like to thank Dr. Belinda Lee for her advice on patient evaluation and questionnaire and Dr. Richard Szydlo for his help with P value derivation.

\section{Conflict of Interest Statement}

The authors report no conflict of interest. 


\section{References}

1. Lecouvet FE, Vande Berg BC, Maldague BE, Michaux L, Laterre E, Michaux JL, Ferrant A, Malghem J. Vertebral compression fractures in multiple myeloma. PartI. Distribution and appearance at MR imaging. Radiology 1997; 204: 195 - 199

2. Nicola N, Lins E. Vertebral haemangioma: retrograde embolizationstabilization with methyl methacrylate. Surg Neurol 1987; 27: 481-486

3. Deramond H, Saliou G, Aveillan M, Lehmann P, Vallée JN. Respective contributions of vertebroplasty and kyphoplasty to the management of osteoporotic vertebral fractures. Joint Bone Spine. 2006 Dec;73(6):610-3

4. Lee B, Franklin I, Lewis JS, Coombes RC, Leonard R, Gishen P, Stebbing J. The efficacy of percutaneous vertebroplasty for vertebral metastases associated with solid malignancies. Eur J Cancer. 2009 Jun;45(9):1597602

5. Tran Thang N, Abdo G, Martin J-B, Seium-Neberay Y, Yilmaz H, Verbist M-C, Rufenacht D, Sappino A-P, Dietrich P-Y. Percutaneous cementoplasty in multiple myeloma: a valuable adjunct for pain control and ambulation maintenance. Support Care Cancer. 2008; 16:891-896

6. Oken MM, Creech RH, Tormey DC, et al. (1982). "Toxicity and response criteria of the Eastern Cooperative Oncology Group". Am. J. Clin. Oncol. 5 (6): 649-55

7. Ramos L, Las Heras JA, Sanchez S, Gonzalez-Porras JR, Gonzalez R, Mateos MV, San Miguel JF. Medium-term results of percuteneous vertebroplasty in multiple myeloma. Eur. J. Haematol. 2006; 77:7-13

8. Cotton A, Dewatre F, Cortet B, Assaker R, Leblond D, Desquesnoy B, Chastanet P, Clarisse J. Percutaneous vertebroplasty for osteolytic metastases and myeloma: effects of the percentage of lesion filling and the leakage of methylmethacrylate at clinical follow-up. Radiology. 1996; 200;525-530

9. Bartolozzi B, Nozzoli C, Pandolfo C, Antonioli E, Guizzardi G, Morichi R, Bosi A. Percuteneous vertebroplasty and kyphoplasty in patients with multiple myeloma. Eur. J. Haematol. 2006; 76:180-181

10. Buchbinder R, Osborne RH, Ebeling PR, Wark JD, Mitchell P, Wriedt C, Graves S, Staples MP, Murphy B. A randomized trial of vertebroplasty for painful osteoporotic vertebral fractures. N Engl. J. Med. 2009; 361,6,557568 
11. Kallmes D, Comstock BA, Heagerty PJ, Turner JA, Wilson DJ, Diamond TH, Edwards R, Gray LA, Stout L, Owen S, Hollingworth W, Ghdoke B, Annesley-Williams DJ, Ralston SH, Jarvik JG. N Engl. J. Med. 2009 $361,6,569-579$

12. Tian $\mathrm{E}$, Zhan $\mathrm{F}$, Walker $\mathrm{R}$, et al. The role of the $\mathrm{Wnt} / b$-catenin signaling antagonist DKK1 in the development of osteolytic lesions in multiple myeloma. N Engl J Med 2003;349:2483-94.

13. Roodman GD, Mechanisms of Bone Metastasis, $\mathrm{N}$ Engl $\mathrm{J}$ Med 2004;350:1655-64

14. Movrin I, Vengust R, Komadina Adjacent vertebral fractures after percutaneous vertebral augmentation of osteoporotic vertebral compression fracture: a comparison of balloon kyphoplasty and vertebroplasty.RArch Orthop Trauma Surg. 2010 May 7. [Epub ahead of print]

15. Kamil Cagri Kose, Oguz Cebesoy, Burak Akan, Levent Altinel, Derya Dincer, Tarik Yazar, Functional results of vertebral augmentation techniques in pathological vertebral fractures of myelomatous patients. J Nat. Med. Assoc., 2006;98;10, 1654-58

16. Bartolozzi B, Nozzoli C, Pandolfo C, Antonioli E, Guizzardi G, Morichi R, Bosi A. Percutaneous Vertebroplasty and Kyphoplasty in patients with multiple myeloma. Eur J Haematol 2006; 76, 180-181

17. Weill A, Chiras J, Simon JM, Rose M, Sola-Martinez T, Enkaoua E. Spinal metastases: indications for and results of percutaneous injection of acrylic surgical cement. Radiology. 1996, 199: 241-247

18. Chakrabarti I, Burton AW, Rao G, Feiz-Erfan I, Hlatky R, Rhines LD, Mendel E. Percutaneous vertebroplasty of a myelomatous compression fracture in the presence of previous posterior instrumentation: Report of two cases. J Neurosurg Spine 5: 168-171, 2006

19. Oakland RJ, Furtado NR, Timothy J, Hall RM. The biomechanics of vertebroplasty in multiple myeloma and metastatic bladder cancer: a preliminary cadaveric investigation. J Neurosurg Spine 9:439 - 501, 2008

20. San Milan RD, Burkhardt K, Jean B, Muster M, Martin JB, Bouvier J, Fasel JH, Rufenacht DA, Kurt AM. Pathology findings with acrylic implants. Bone, 1999, 25: 85S-90S 
21. Kuo PH, Cheng DW. Artifactual Spinal Metastases Imaged by PET/CT:

A Case Report. J Nucl Med Technol 2005; 33:230-231

22. Fossaceca R, Di Terlizzi M, Stecco A, Canalis L, Travaglini F, Ambrosini

R, Carriero A. MRI Post-vertebroplasty, Radiol Med (2007), 112:185-194

23. Rodriguez-Catarino M, Blimark C, Willen J, Mellqvist U, Rodjer S.

Percutaneous Vertebroplasty at C2: case report of a patient with multiple myeloma and a literature review. Eur Spine J (2007) 16 (Suppl 3): S242S249

24. Zhou B, Wu C, Li M, Gu Y, Cheng Y. Percutaneous osteoplasty for painful sterna lesion from multiple myeloma. Skeletal Radiol (2009) 38:281-285

25. Mont'Alverne F, Vallee J, Guillevin R, Cormier E, Jean B, Rose M, Caldas JG, Chiras J. Percutaneous Vertebroplasty for Multiple myeloma of the Cervical Spine. Neuroradiology (2009) 51:237-242 


\section{Tables and Legends}

Table I. Characteristics of patients who underwent vertebroplasty for pain control secondary myeloma related spinal column lesions

Abbreviations: $\mathrm{M}=$ male; $\mathrm{F}=$ female $; \mathrm{VAD}=$ vincristine + doxorubicin + dexamethasone; $\mathrm{CTD}=$ cyclophosphamide + thalidomide + dexamethasone; VelDex = bortezomib + dexamethasone; ZDex = idarubicin + dexamethasone; Thal = Thalidomide; auto = stem cell autograft; sib allo = sibling stem cell allograft

\begin{tabular}{|c|c|c|c|c|c|c|c|c|c|}
\hline Patient & Age / Sex & $\begin{array}{l}\text { Vertebral levels } \\
\text { treated }\end{array}$ & $\begin{array}{l}\text { No. of } \\
\text { sites }\end{array}$ & $\begin{array}{l}\text { Pain pre } \\
\text { Prior }\end{array}$ & Pain Benefit? & $\begin{array}{l}\text { Systemic } \\
\text { Chemotherapy } \\
\text { pre - } \\
\text { vertebroplasty? }\end{array}$ & Bisphosphonate & $\begin{array}{l}\text { Radiotherapy } \\
\text { (Pre / post } \\
\text { vertebroplasty) }\end{array}$ & Surgery \\
\hline 1 & $71(\mathrm{M})$ & $\mathrm{T} 12, \mathrm{~L} 1$ & 2 & Moderate & Yes & VAD & Zoledronic acid & No & No \\
\hline 2 & $64(\mathrm{~F})$ & T11, L1 & 2 & Severe & No & VAD / auto & Zoledronic acid & No & No \\
\hline 3 & $51(\mathrm{~F})$ & T12, L2 & 2 & Severe & No & VAD / CTD & Zoledronic acid & Yes - pre & No \\
\hline 4 & $51(\mathrm{M})$ & T12, L1, L3 & 3 & Severe & Yes & $\begin{array}{l}\text { CD / VAD / CTD } \\
\text { /auto / VelDex }\end{array}$ & Pamidronate & Yes - pre & No \\
\hline 5 & $70(\mathrm{M})$ & $\mathrm{T} 6$ & 1 & Moderate & No & No & No & Yes - post & No \\
\hline 6 & $65(\mathrm{~F})$ & $\mathrm{T} 12, \mathrm{~L} 2$ & 2 & Moderate & Yes & ZDex / auto / Thal & Zoledronic acid & Yes - pre & No \\
\hline 7 & $71(\mathrm{M})$ & $\mathrm{T} 8, \mathrm{~T} 11, \mathrm{~L} 1$ & 3 & Severe & Yes & VAD & $\begin{array}{c}\text { Sodium } \\
\text { clodronate }\end{array}$ & No & No \\
\hline 8 & $54(\mathrm{~F})$ & L1, L2, L3 & 3 & Severe & No & VAD / auto & Zoledronic acid & Yes - post & No \\
\hline 9 & $51(\mathrm{~F})$ & T6, T7, T8 & 3 & Severe & Yes & $\mathrm{VAD} / \mathrm{ZDex} /$ auto & pamidronate & Yes - pre & No \\
\hline
\end{tabular}




\begin{tabular}{|c|c|c|c|c|c|c|c|c|c|}
\hline 10 & $44(\mathrm{M})$ & $\mathrm{T} 12$ & 1 & Severe & Yes & $\mathrm{CTD} / \mathrm{VAD}$ & $\begin{array}{c}\text { Sodium } \\
\text { clodronate then } \\
\text { zoledronic acid }\end{array}$ & Yes - post & $\begin{array}{l}\text { Yes } 4 \text { months } \\
\text { post } \\
\text { vertebroplasty }\end{array}$ \\
\hline 11 & $76(\mathrm{M})$ & L4 & 1 & Moderate & Yes & VAD & pamidronate & Yes - pre & No \\
\hline 12 & $53(\mathrm{~F})$ & $\mathrm{T} 9, \mathrm{~T} 11, \mathrm{~T} 12$ & 3 & Severe & Yes & CTD/ Thal / auto & pamidronate & Yes - pre & No \\
\hline 13 & $44(\mathrm{M})$ & $\mathrm{T} 12$ & 1 & Moderate & Yes & $\begin{array}{c}\text { VAD / CTD / } \\
\text { auto }\end{array}$ & $\begin{array}{c}\text { Sodium } \\
\text { clodronate }\end{array}$ & Yes - pre & No \\
\hline 14 & $71(\mathrm{M})$ & T12, L1, L3 & 3 & Moderate & Yes & CTD / Thal & $\begin{array}{l}\text { Sodium } \\
\text { clodronate }\end{array}$ & No & No \\
\hline 15 & $54(\mathrm{~F})$ & $\mathrm{T} 11, \mathrm{~L} 1, \mathrm{~L} 3$ & 3 & Severe & No & No & Aledronic acid & No & No \\
\hline 16 & $42(\mathrm{~F})$ & L1 & 1 & Severe & Yes & VAD / sib. allo & No & Yes pre and post & No \\
\hline 17 & $61(\mathrm{M})$ & $\mathrm{T} 12$ & 1 & Severe & Yes & $\begin{array}{c}\text { ZDex / CTD / } \\
\text { auto/ Thal }\end{array}$ & $\begin{array}{c}\text { Zoledronic acid } \\
\text { then sodium } \\
\text { clodronate }\end{array}$ & No & $\begin{array}{c}\text { Had had previous } \\
\text { T11 - L1 spinal } \\
\text { surgery }\end{array}$ \\
\hline 18 & $71(\mathrm{~F})$ & L1, L3, L4 & 3 & Moderate & Yes & CTD / bortezomib & $\begin{array}{c}\text { Stopped as } \\
\text { osteonecrosis of } \\
\text { jaw }\end{array}$ & No & No \\
\hline 19 & $64(\mathrm{M})$ & $\mathrm{T} 12, \mathrm{~L} 4, \mathrm{~L} 5$ & 3 & Moderate & Yes & $\begin{array}{c}\text { VAD / auto / } \\
\text { CTD }\end{array}$ & $\begin{array}{l}\text { Sodium } \\
\text { clodronate }\end{array}$ & Yes - pre & $\begin{array}{l}\text { No surgery, but } \\
\text { had kyphoplasty } \\
\text { to } 2 \text { further } \\
\text { vertebrae }\end{array}$ \\
\hline 20 & $57(\mathrm{M})$ & $\mathrm{T} 12$ & 1 & Severe & Yes & $\begin{array}{c}\mathrm{VAD} / \text { auto / } \\
\mathrm{CTD} / \text { bortezomib }\end{array}$ & Pamidronate & No & No \\
\hline 21 & $57(\mathrm{~F})$ & T9, T10, T11 & 3 & Severe & Yes & $\begin{array}{c}\text { VAD / auto / } \\
\text { CTD }\end{array}$ & Zoledronic acid & Yes - pre & No \\
\hline
\end{tabular}




\begin{tabular}{|c|c|c|c|c|c|c|c|c|c|}
\hline 22 & $60(\mathrm{M})$ & $\mathrm{T} 11, \mathrm{~T} 12, \mathrm{~L} 1$ & 3 & Severe. & Yes & $\begin{array}{c}\mathrm{VAD} / \text { auto / sib } \\
\text { allo }\end{array}$ & No & Yes - pre & No \\
\hline 23 & $45(\mathrm{M})$ & $\mathrm{T} 11$ & 1 & Severe & Yes & CTD & $\begin{array}{c}\text { Pamidronate then } \\
\text { zoledronic acid }\end{array}$ & No & No \\
\hline 24 & $75(\mathrm{M})$ & $\mathrm{L} 1, \mathrm{~L} 2$ & 2 & Moderate & No & No & No & Yes - pre & $\begin{array}{l}\text { Had had previous } \\
\text { L4-L5 surgery }\end{array}$ \\
\hline 25 & $69(\mathrm{M})$ & $\mathrm{L} 2, \mathrm{~L} 4, \mathrm{~L} 5$ & 3 & Severe & Yes & CTD / Thal / auto & Zoledronic acid & Yes - post & No \\
\hline 26 & $52(\mathrm{M})$ & $\mathrm{L} 3, \mathrm{~L} 4, \mathrm{~L} 5$ & 3 & Severe & Yes & ThalDex & No & No & No \\
\hline
\end{tabular}




\section{Figures and Legends}

Figure 1. Panels A and B indicate anteroposterior and left lateral views of the insertion of the vertebroplasty needles. One or two needles are placed via a transpeduncular approach and inserted to the area of collapse (frequently anterior one third of the vertebral body) Panels C and D illustrate, in the same orientations, the placement of the PMMS cement into the vertebra. The cement pathway within the vertebral body follows the low resistance direction. Most procedures are achievable using a single needle approach.
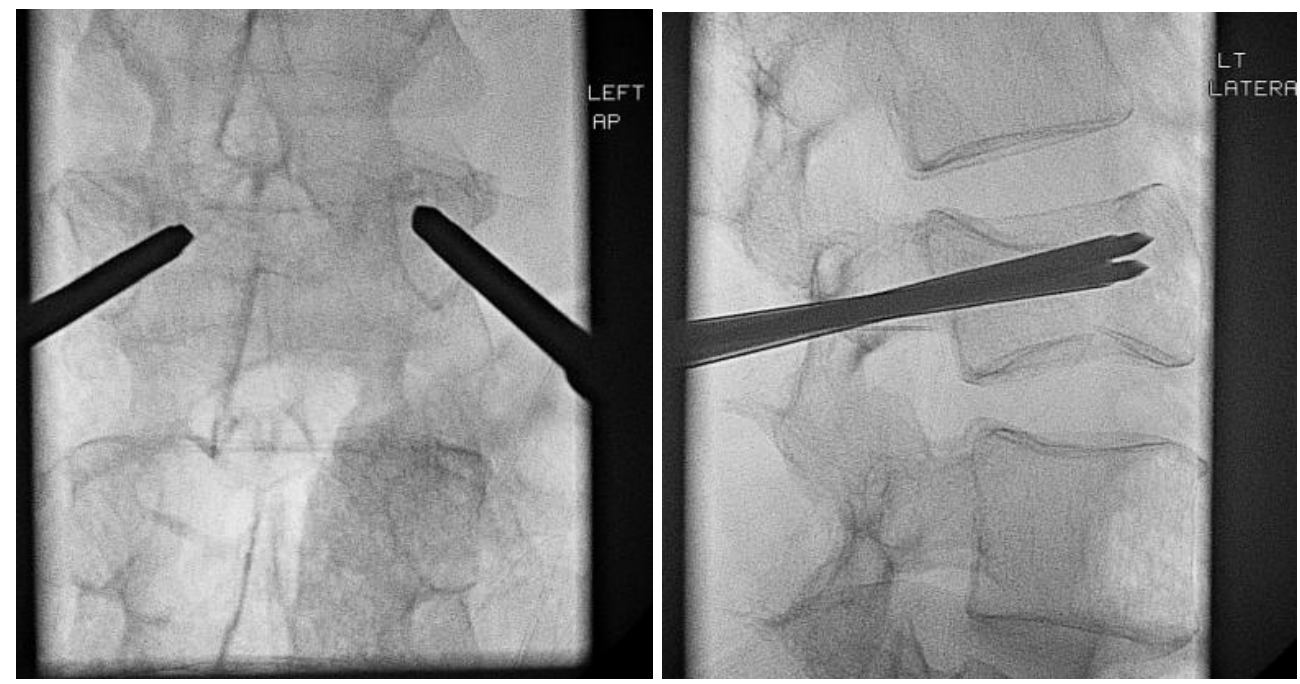

Panel A

Panel B
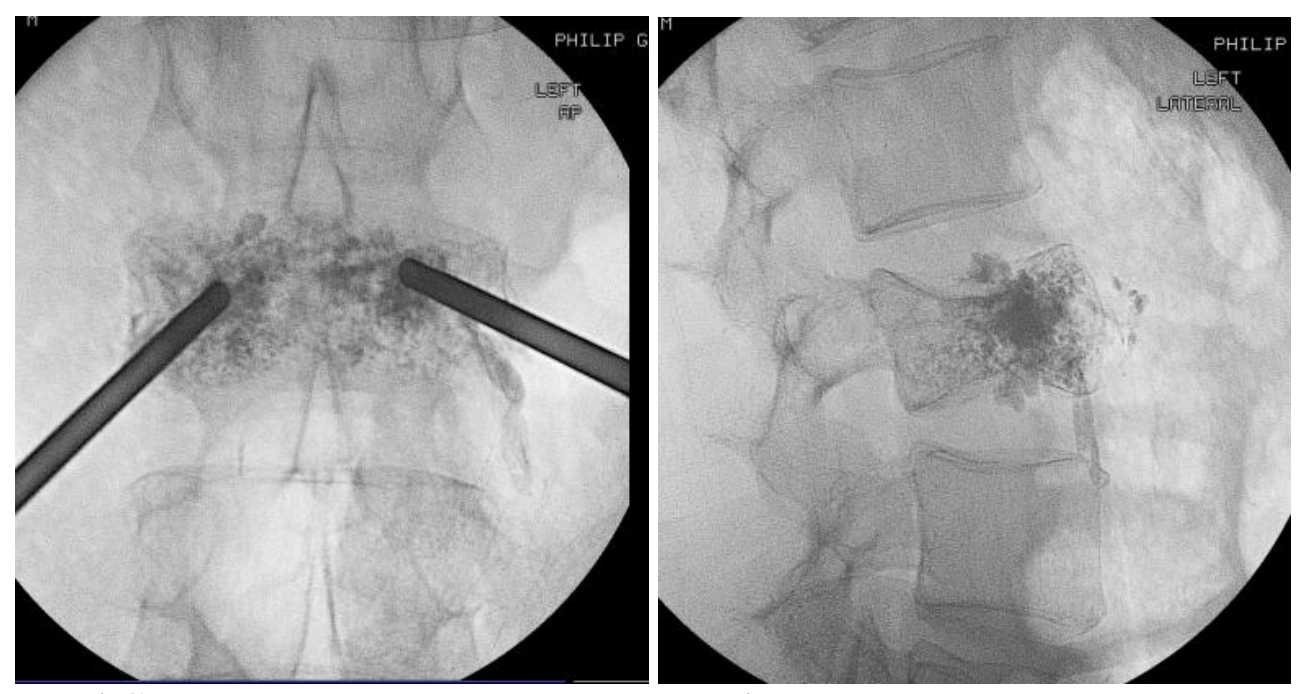

Panel C

Panel D 